\title{
Post-abortion family planning use, method preference, and its determinant factors in Eastern Africa: a systematic review and meta-analysis
}

\author{
Asmamaw Demis Bizuneh ${ }^{1 *}$ and Getnet Gedefaw Azeze ${ }^{2}$
}

\begin{abstract}
Background: Utilization of post-abortion family planning is very critical to reduce high levels of unintended pregnancy, which is the root cause of induced abortion. In Eastern Africa, it is estimated that as many as 95\% of unintended pregnancies occurred among women who do not practice contraception at all. Therefore, this metaanalysis aimed to assess post-abortion family planning utilization and its determinant factors in Eastern Africa.

Methods: Published papers from Scopus, HINARI, PubMed, Google Scholar, and Web of Science electronic databases and grey literature repository were searched from database inception to January 30, 2020, with no restriction by design and date of publishing. We screened records, extracted data, and assessed risk of bias in duplicate. Cochrane $I^{2}$ statistics were used to check the heterogeneity of the studies. Publication bias was assessed by Egger and Biggs test with a funnel plot. A random-effects model was calculated to estimate the pooled prevalence of post-abortion family planning utilization.

Results: A total of twenty-nine cross-sectional studies with 70,037 study participants were included. The overall pooled prevalence of post-abortion family planning utilization was $67.86 \%$ (95\% Cl 63.59-72.12). The most widely utilized post-abortion family methods were injectable 33.23\% (95\% Cl 22.12-44.34), followed by implants $24.71 \%$ (95\% Cl 13.53-35.89) and oral contraceptive pills 23.42\% (95\% Cl 19.95-26.89). Married marital status (AOR=3.20; $95 \% \mathrm{Cl} 2.02-5.05$ ), multiparity ( $\mathrm{AOR}=3.84$; $95 \% \mathrm{Cl} 1.43-10.33$ ), having a history of abortion ( $\mathrm{AOR}=2.33$; $95 \% \mathrm{Cl} 1.44-$ 3.75), getting counselling on post-abortion family planning ( $\mathrm{AOR}=4.63 ; 95 \% \mathrm{Cl} 3.27-6.56$ ), and ever use of contraceptives (AOR=4.63; 95\% Cl 2.27-5.21) were factors associated with post-abortion family planning utilization in Eastern Africa.

Conclusions: This study revealed that the marital status of the women, multiparity, having a history of abortion, getting counselling on post-abortion family planning, and ever used contraceptives were found to be significantly associated with post-abortion family planning utilization.
\end{abstract}

Keywords: Post-abortion, Family planning, Systematic review, Meta-analysis, Eastern Africa

\footnotetext{
*Correspondence: asmamawdemis@gmail.com

${ }^{1}$ School of Nursing, College of Health Sciences, Woldia University, P.O.Box: 400, Woldia, Ethiopia

Full list of author information is available at the end of the article
}

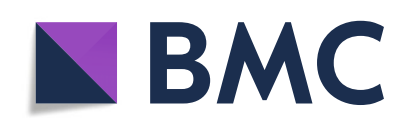

(- The Author(s). 2021 Open Access This article is licensed under a Creative Commons Attribution 4.0 International License, which permits use, sharing, adaptation, distribution and reproduction in any medium or format, as long as you give appropriate credit to the original author(s) and the source, provide a link to the Creative Commons licence, and indicate if changes were made. The images or other third party material in this article are included in the article's Creative Commons licence, unless indicated otherwise in a credit line to the material. If material is not included in the article's Creative Commons licence and your intended use is not permitted by statutory regulation or exceeds the permitted use, you will need to obtain permission directly from the copyright holder. To view a copy of this licence, visit http://creativecommons.org/licenses/by/4.0/. The Creative Commons Public Domain Dedication waiver (http://creativecommons.org/publicdomain/zero/1.0/) applies to the data made available in this article, unless otherwise stated in a credit line to the data. 


\section{Background}

Post-abortion family planning is the initiation and use of family planning methods immediately after and within $48 \mathrm{~h}$ of an induced or spontaneous abortion or treatment of complications before fertility returns $[1,2]$. The provision of family planning is important for women in the post-abortion period because fertility can return surprisingly quickly after having an abortion. Even if a woman wants to have a child immediately after an abortion, the World Health Organization (WHO) and Federation of International Gynaecology and Obstetrics (FIGO) guidelines recommend she should wait at least 6 months before getting pregnant again $[2,3]$. The global estimates for the year 2017 indicate that there were 295, 000 maternal deaths worldwide, with Sub-Saharan Africa and Southern Asia accounting for approximately 86\% $(254,000)$, with Eastern Africa alone accounting for roughly 542/100,000 maternal deaths [4].

Every year, more than 44 million women have been complicated with induced abortions, and of these, around 20 million women accounted for unsafe abortions. Unsafe abortion contributes to $13 \%$ of maternal deaths globally and 37 deaths per 100,000 live births in Sub-Saharan Africa (SSA). The World Health Organization (WHO) estimates that in Eastern Africa unsafe abortion accounts for one in seven maternal deaths [1, 5]. In Africa, 99\% of all abortions carried out were unsafe, and the risk of maternal death from an unsafe abortion is one in every 150 procedures which is the highest in the world [6, 7].

Offering a wide range of post-abortion family planning methods is likely to increase family planning uptake; as a result, in the immediate post-abortion period, WHO recommended that a woman can safely use a full range of contraceptive methods, including condoms, spermicides, oral contraceptives, emergency contraceptive pills, injectable, implants, IUDs, and female sterilization [8]. Almost every abortion-related death and disability could be prevented through sexuality education; use of effective contraception; provision of safe, legal-induced abortion; and timely care for complications. Post-abortion family planning (PAFP) has been proposed as a key strategy to reduce unintended pregnancy, repeatinduced abortions and lower morbidity and mortality among women, neonates, infants, and children [9-11]. However, the accessibility and quality of PAFP services remain a challenge in Eastern Africa where a higher number of unintended pregnancies occur each year. In Eastern Africa, a lot of fragmented studies have been conducted to assess post-abortion family planning utilization and its associated factors among post-aborted women. These fragmented studies reported that the magnitude of post-abortion family planning utilization in Eastern Africa ranged from 15.5 to $90.6 \%$ [12-20].
From the reports of these studies, there was a great variation and inconsistency related to the prevalence of post-abortion family planning utilization throughout East African countries.

The reasons for the above variation in the prevalence and associated factors of post-abortion family planning utilization among East African women have not yet been investigated. The provision of safe, legal abortion is essential to fulfilling the global commitment to the Sustainable Development Goal (SDGs) of universal access to sexual and reproductive health (target 3.7). A systematic review and meta-analysis would help policymakers and health managers and planners to make evidencebased decisions that have taken into account all available information, as well as indicating the quality of the results. Therefore, the main aim of this systematic review and meta-analysis was to estimate the pooled prevalence of post-abortion family planning utilization and to identify its associated factors among post-aborted women that could be used in policy formulation and evidencebased decision-making practices in Eastern Africa.

\section{Materials and methods Study reporting}

In this systematic review and meta-analysis, we used the "Preferred Reporting Items for Systematic Reviews and Meta-Analyses (PRISMA)" guideline [21] (Table S1).

\section{Databases and search strategies}

In this systematic review and meta-analysis, we checked databases without the restriction of design and date of publishing. The search included keywords and $\mathrm{MeSH}$ terms, combinations, and snowball searching about relevant papers providing data on the prevalence of postabortion family planning utilization and/or its associated factors in a search focused on eastern Africa. Studies were searched from databases including PubMed/MEDLINE, Web of Science, Embase, Scopus, HINARI, Science Direct, African Journals, and Cochrane Library. Besides, bibliographies of identified articles and grey literature, like Google and Google scholar, Mednar, World Wide Science, and online University repositories have been scientifically searched (Table 1). The following websites were hand-searched: Ipas, Jhpiego, Family Health International, Marie Stopes International, Population Council, Post-abortion Care Consortium, Gynuity Health Projects Engender Health, PRIME II, and Eldis. The following search terms were used: (Prevalence OR Epidemiology OR Magnitude) AND (determinants OR associated factors OR predictors) AND (Post-abortion OR postabortion OR postabortal OR post abortal OR post-abortal OR incomplete abortion OR incomplete abortions OR unsafe abortion OR unsafe abortions AND (family planning use OR family planning utilization OR 
Table 1 Search strategy for the MEDLINE/PubMed and Google Scholar databases to assess post-abortion family planning utilization and its associated factors in eastern Africa

\begin{tabular}{|c|c|c|}
\hline Databases & Searching terms & $\begin{array}{l}\text { Number of } \\
\text { studies }\end{array}$ \\
\hline MEDLINE/PubMed & $\begin{array}{l}\text { (Prevalence OR Epidemiology OR Magnitude) AND (determinants OR associated factors OR predictors) AND } \\
\text { (Post-abortion OR postabortion OR postabortal OR post abortal OR post-abortal OR incomplete abortion OR } \\
\text { incomplete abortions OR unsafe abortion OR unsafe abortions) AND (family planning use OR family planning } \\
\text { utilization OR family planning uptake OR family planning services OR contraceptive use OR contraceptive } \\
\text { utilization OR contraceptive uptake OR birth control OR fertility control OR population control) AND (east } \\
\text { Africa) }\end{array}$ & 2233 \\
\hline Google Scholar & $\begin{array}{l}\text { "Prevalence AND determinants OR associated factors AND Post-abortion AND family planning use OR family } \\
\text { planning utilization OR family planning uptake OR family planning services OR contraceptive use OR contra- } \\
\text { ceptive utilization OR contraceptive uptake AND east Africa." }\end{array}$ & 1530 \\
\hline $\begin{array}{l}\text { From other } \\
\text { databases }\end{array}$ & & 598 \\
\hline $\begin{array}{l}\text { Total retrieved } \\
\text { articles }\end{array}$ & & 4361 \\
\hline $\begin{array}{l}\text { Number of included } \\
\text { studies }\end{array}$ & & 29 \\
\hline
\end{tabular}

family planning uptake OR family planning services OR contraceptive use OR contraceptive utilization OR contraceptive uptake OR birth control OR fertility control OR population control) AND (east Africa) and related terms. All countries are categorized under Eastern Africa, namely, Kenya, Uganda, Tanzania, Rwanda, Burundi, Ethiopia, South Sudan, Djibouti, Eritrea, Mozambique, Madagascar, Malawi, Zambia, Comoros, Mauritius, Seychelles, and Somalia. The search terms were used independently and in amalgamation using Boolean operators like "OR" or "AND" and related terms. All article searched from databases was exported to EndNote library. Systematic review with narrative synthesis was used to summarize the findings of articles in Eastern Africa.

\section{Inclusion and exclusion criteria}

In this systematic review and meta-analysis, both published and unpublished articles in the English language without time limiting that reported prevalence of postabortion family planning utilization and/or its associated factors among women in Eastern Africa were included. Articles searched from January 1-30, 2020, were included. Additionally, we restricted our search to observational studies such as cross-sectional, comparative cross-sectional, case-control, and retrospective and prospective cohort studies. Interventional studies, case reports, letters, editorials, systematic reviews, narrative reviews, policy statements, news, and inaccessible full text after two contact attempts of the corresponding author by email were excluded from the final analysis.

\section{Data extraction}

After removing duplicates from the Endnote version X8 software, all studies were exported to a Microsoft Excel spreadsheet. Two authors (ADB and GGA) independently extracted all important data using a standardized data extraction form which was adapted from the JBI data extraction format. Substantial agreement between reviewers, i.e., Cohen's kappa coefficient $>0.60$, was accepted and resolved through discussion and consensus. For the first outcome (prevalence), the data extraction format included (primary author, year of publication, country, study area, sample size, and prevalence with $95 \%$ CI). Data were extracted with a 2 by 2 table format, and then, the log odds ratio for each factor was calculated for the second outcome (associated factors).

\section{Measurement of outcomes}

This meta-analysis had two outcomes. The first outcome of this study mainly focused on the prevalence of postabortion family planning utilization in Eastern Africa. The prevalence was calculated by dividing the number of women who used post-abortion family planning by the total number of women who have been included in the study (sample size) multiplied by 100 . The second outcome of the study was factors associated with postabortion family planning utilization, which were measured by using the adjusted odds ratio from primary published studies.

\section{Quality evaluation}

Two authors (ADB and GGA) independently assessed the quality of each study using Newcastle-Ottawa scale (NOS) for cross-sectional studies [22]. All included articles were cross-sectional in design. The methodological quality of the study, comparability of the study, and the outcome and statistical analysis of the study were the three major assessment tools we used to declare the quality of the study. Lastly, studies that scored a scale of $\geq 7$ out of 10 were considered as achieving high quality. 
During quality appraisal of the articles, any discrepancies between the two authors were resolved.

\section{Data synthesis and statistical analysis}

We pooled the overall prevalence estimates of postabortion family planning utilization using the randomeffects model [23]. After extraction of the articles in Microsoft Excel spreadsheet format, the analysis was carried out using the STATA version 14 statistical software. Cochrane Q test and $I^{2}$ statistics were computed to assess heterogeneity among studies [23, 24]. After computing the statistics, the results showed there was significant heterogeneity among the studies $\left(I^{2}=99.2 \%\right.$, $\mathrm{p}<0.001$ ); therefore, considerable heterogeneity was assumed, and Mantel-Haenszel random-effects model meta-analysis was employed to estimate the Dersimonian and Laird's pooled effect [25]. Publication bias was also assessed using Egger's correlation and Begg's regression intercept tests at a 5\% significance level $[26,27]$. Due to the presence of publication bias in the study, Egger's test was statistically significant $(\mathrm{p}=0.006)$; as a result, trim-fill analysis was executed. Subgroup analysis was done by the study country, sample size, and year of publication to minimize the random variations between the point estimates of the primary study. Forest plot format was used to present the pooled point prevalence with $95 \%$ CI. For associations, a log odds ratio was used to decide the association between associated factors and post-abortion family planning utilization.

\section{Results}

Of the total retrieved articles from different databases, 1420 articles remained after expunging the duplicates. Out of the remaining articles, 925 and 403 were excluded after reviewing the titles and abstracts, respectively. Therefore, 92 full-text articles were accessed and assessed for eligibility based on the preset criteria, which resulted in the further exclusion of 63 articles primarily due to the outcome of interest not reported $(n=61)$ and inaccessibility of the full text $(n=2)$. As a result, 29 studies meeting the eligibility criteria were included in the final meta-analysis (Fig. 1).

\section{Characteristics of original studies}

Among the 29 articles which were published in East African countries until January 2020, 70,037 study participants were involved to determine the pooled prevalence of post-abortion family planning utilization. Regarding the study design, all studies were cross-sectional. Fifteen of the studies were from Ethiopia [15-18, 28-38], five studies were from Kenya [20, 39-42], four studies were from Tanzania [43-46], and the rest five studies were from Malawi [47], Mozambique [48], Zimbabwe [49], Somalia [50], and Rwanda [51]. Regarding the quality

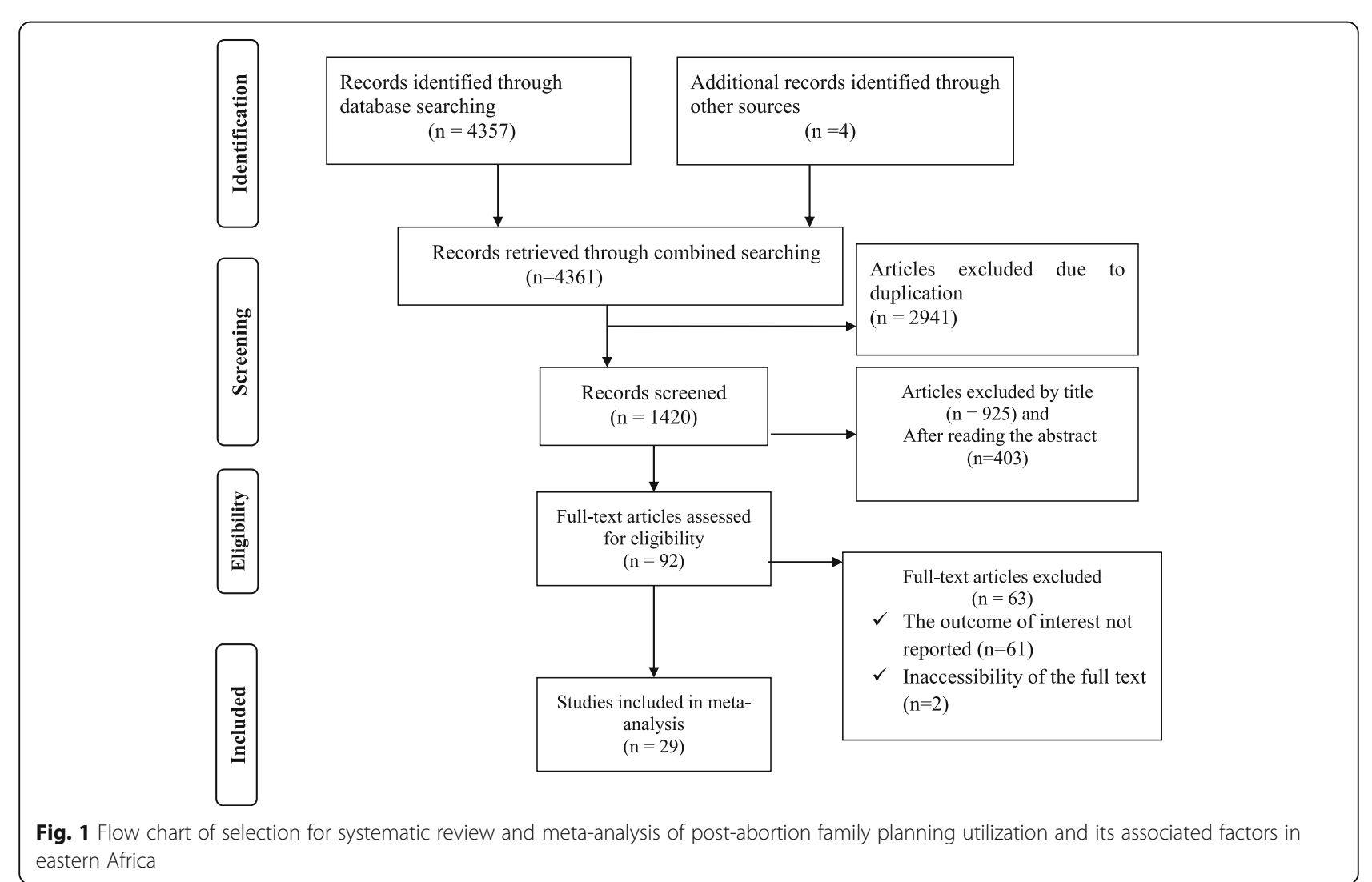


scores, the quality score of each original study ranged from a low of six to a high of eight (Table 2).

Post-abortion family planning utilization in eastern Africa In this systematic review and meta-analysis, the overall pooled prevalence of post-abortion family planning utilization was $67.86 \%$ (95\% CI 63.59-72.12) (Fig. 2).

\section{Heterogeneity and publication bias}

The existence of heterogeneity within the included studies was declared with the evidence of $\mathrm{I}^{2}=99.2 \%$. The evidence of asymmetric distribution of the funnel plot and the statistically significant $(p=0.006)$ value of Egger's test showed the presence of publication bias (Fig. 3).

\section{Trim-fill analysis}

In this meta-analysis, due to the presence of publication bias, we executed a trim-fill analysis by using a randomeffects model; the filled meta-analysis results showed that three studies were filled, which increases the number of studies from 29 to 32 with the pooled estimate for post-abortion family planning utilization in Eastern Africa was $65.08 \%$ (95\% CI 59.42-70.73, $p<0.0001$ ) (Fig. 4).

\section{Subgroup analysis}

Due to the presence of heterogeneity within the included studies, a subgroup analysis based on the country, year of publication, and the sample size was conducted to identify the source of heterogeneity. Accordingly, the highest prevalence was observed in Zimbabwe with 91.97\% (95\% CI 90.29-93.65), and the lowest prevalence

Table 2 Study characteristics included in the systematic review and meta-analysis on post-abortion family planning utilization and its associated factors in Eastern Africa

\begin{tabular}{|c|c|c|c|c|c|c|}
\hline Authors & Country & Publication year & Study design & Sample size & Prevalence & Quality \\
\hline Abamecha et al. [15] & Ethiopia & 2016 & Cross-sectional & 399 & 72.93 & 7 \\
\hline Abebe et al. [18] & Ethiopia & 2019 & Cross-sectional & 125 & 84.00 & 8 \\
\hline Alemayehu et al. [38] & Ethiopia & 2009 & Cross-sectional & 2231 & 78.26 & 7 \\
\hline Asrat et al. [16] & Ethiopia & 2018 & Cross-sectional & 552 & 90.58 & 7 \\
\hline Chukwumalu et al. [50] & Somalia & 2017 & Cross-sectional & 1111 & 85.96 & 8 \\
\hline Erko et al. [37] & Ethiopia & 2016 & Cross-sectional & 184 & 70.11 & 8 \\
\hline Evens et al. [20] & Kenya & 2014 & Cross-sectional & 283 & 15.55 & 8 \\
\hline Gallo et al. [48] & Mozambique & 2004 & Cross-sectional & 332 & 37.05 & 7 \\
\hline Hagos et al. [36] & Ethiopia & 2018 & Cross-sectional & 409 & 70.90 & 8 \\
\hline Kassahun [35] & Ethiopia & 2017 & Cross-sectional & 459 & 68.85 & 7 \\
\hline Kokeb et al. [34] & Ethiopia & 2015 & Cross-sectional & 414 & 59.18 & 8 \\
\hline Lema and Mpanga [47] & Malawi & 2000 & Cross-sectional & 464 & 80.39 & 7 \\
\hline Mahomed et al. [49] & Zimbabwe & 1997 & Cross-sectional & 1009 & 91.97 & 7 \\
\hline Makenzius et al. [42] & Kenya & 2018 & Cross-sectional & 810 & 75.19 & 8 \\
\hline Mekuria et al. [33] & Ethiopia & 2019 & Cross-sectional & 400 & 78.50 & 8 \\
\hline Moges et al. [17] & Ethiopia & 2018 & Cross-sectional & 400 & 61.50 & 7 \\
\hline Muche et al. [32] & Ethiopia & 2019 & Cross-sectional & 371 & 45.82 & 7 \\
\hline Mutua et al. [41] & Kenya & 2019 & Cross-sectional & 2568 & 55.45 & 9 \\
\hline Onyango et al. [40] & Kenya & 2010 & Cross-sectional & 403 & 30.52 & 8 \\
\hline Packer et al. [51] & Rwanda & 2019 & Cross-sectional & 68 & 70.59 & 8 \\
\hline Prata et al. [31] & Ethiopia & 2011 & Cross-sectional & 1200 & 77.67 & 7 \\
\hline Rasch et al. [46] & Tanzania & 2004 & Cross-sectional & 788 & 89.85 & 8 \\
\hline Rasch et al. [45] & Tanzania & 2008 & Cross-sectional & 392 & 88.52 & 7 \\
\hline Samuel et al. [30] & Ethiopia & 2016 & Cross-sectional & 44682 & 80.68 & 8 \\
\hline Seid et al. [29] & Ethiopia & 2012 & Cross-sectional & 282 & 47.52 & 8 \\
\hline Solo et al. [39] & Kenya & 1999 & Cross-sectional & 319 & 48.28 & 7 \\
\hline Stephens et al. [44] & Tanzania & 2019 & Cross-sectional & 8230 & 80.63 & 8 \\
\hline Tesfaye and Oljira [28] & Ethiopia & 2013 & Cross-sectional & 400 & 56.50 & 8 \\
\hline Wanjiru et al. [43] & Tanzania & 2007 & Cross-sectional & 752 & 69.81 & 8 \\
\hline
\end{tabular}




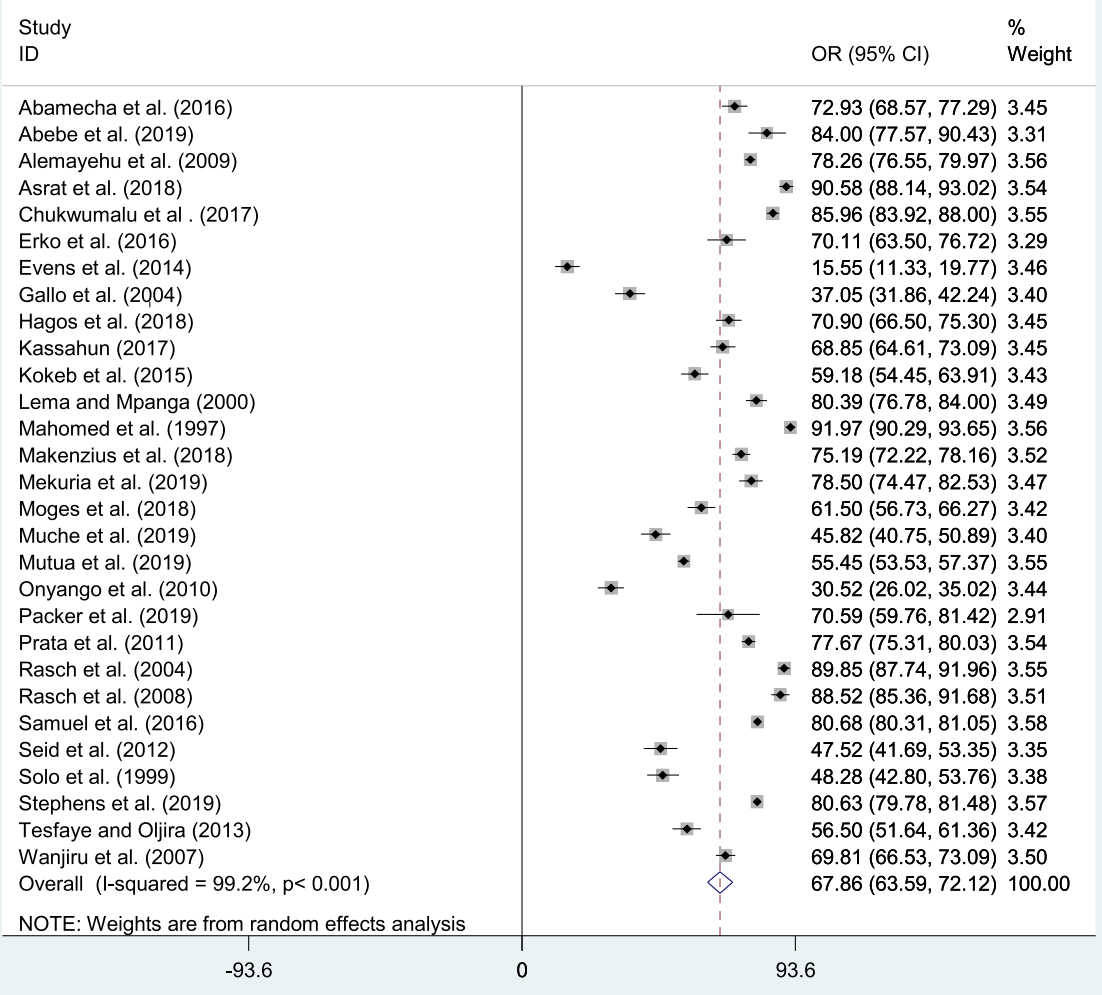

Fig. 2 Forest plot of the pooled prevalence of post-abortion family planning utilization in Eastern Africa

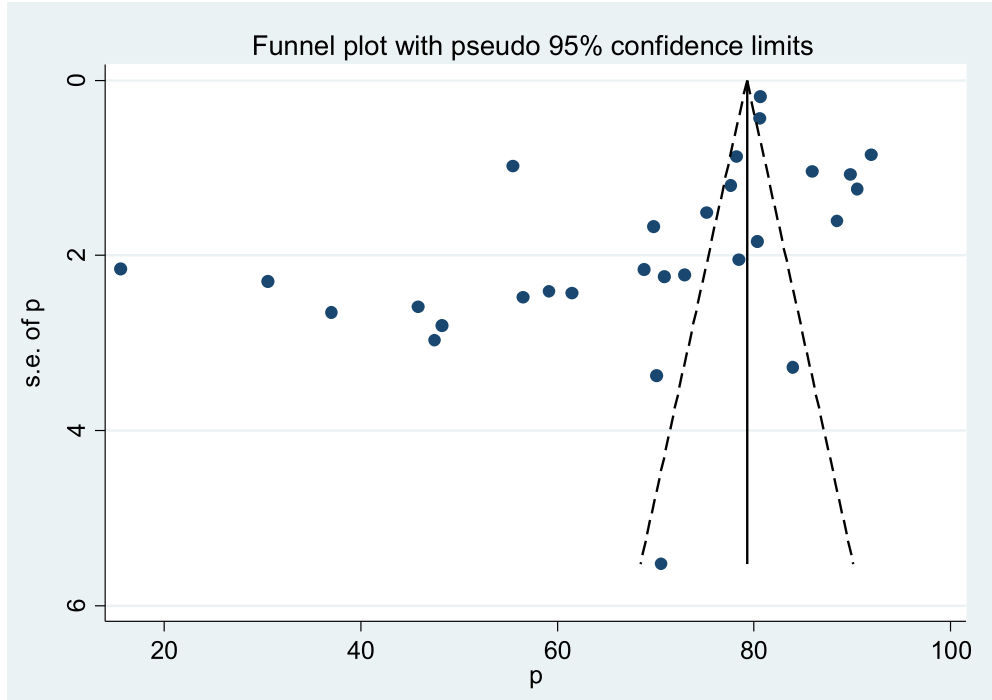

Fig. 3 Funnel plot with 95\% confidence limits of the pooled prevalence of post-abortion family planning utilization in Eastern Africa 
Filled funnel plot with pseudo $95 \%$ confidence limits

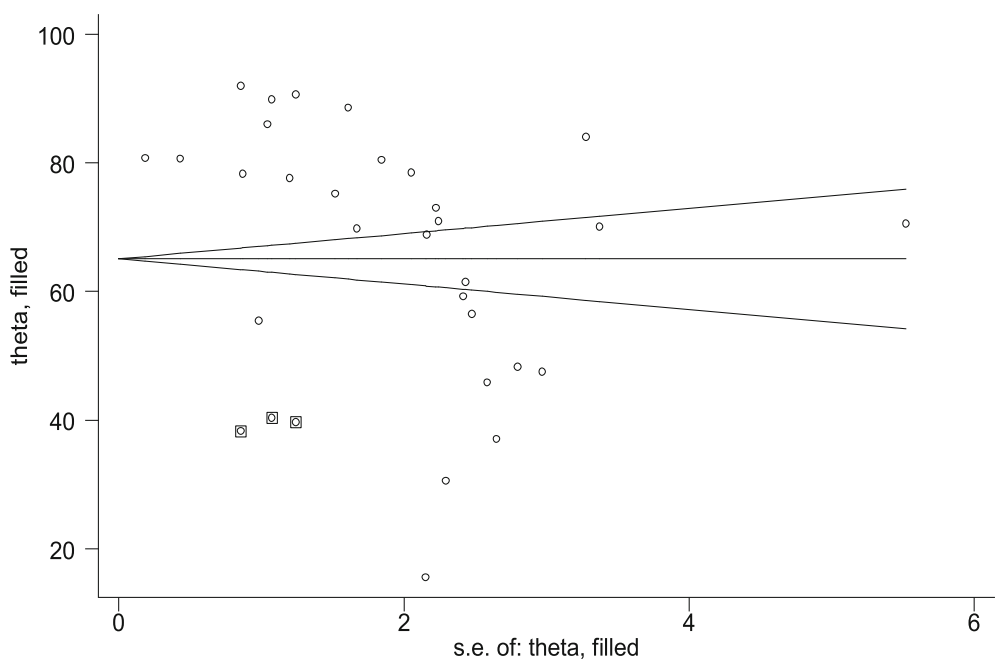

Fig. 4 Trim-fill analysis filled funnel plot with 95\% confidence limits of the pooled prevalence of post-abortion family planning utilization in Eastern Africa

was observed in Mozambique with 37.05\% (95\% CI 31.86-42.24). Regarding sample size, the highest prevalence was observed in studies with a sample size of $\geq 1000$ with $78.68 \%$ (95\% CI 73.42-83.93).

Besides, we also executed a subgroup analysis based on publication year. Accordingly, the highest prevalence of post-abortion family planning utilization has occurred in studies published before 2006, which was 69.70\% ((95\% CI 53.83-85.58), $\left.\mathrm{I}^{2}=99.3, p<0.001\right)$ (Table 3).

Types of post-abortion family planning methods utilized In this meta-analysis, women in post-abortion time utilized the common post-abortion family planning methods, namely, injectable $33.23 \%$ (95\% CI $22.12-$
44.34), implants $24.71 \%$ (95\% CI 13.53-35.89), oral contraceptive pills $23.42 \%$ (95\% CI 19.95-26.89), intrauterine devices $9.12 \%$ (95\% CI 5.36-12.88), and condom 7.43\% (95\% CI 5.17-9.69) (Table 4).

\section{Sensitivity analysis}

We executed a leave-one-out sensitivity analysis to further investigate the potential source of heterogeneity observed in the pooled prevalence of post-abortion family planning utilization in Eastern Africa. Our sensitivity analysis suggested that our findings were robust and not dependent on a single study. The pooled estimated prevalence varied between $66.96(62.59-71.33 \%)$ and

Table 3 Subgroup prevalence of post-abortion family planning utilization in eastern Africa

\begin{tabular}{|c|c|c|c|c|c|}
\hline Variables & Characteristics & Included studies & Number of study participants & Prevalence with $(95 \% \mathrm{Cl})$ & $\mathrm{I}^{2}$, P-value \\
\hline \multirow[t]{2}{*}{ Publication year } & 2006 and above & 24 & 67,125 & $67.42(62.85-71.98)$ & $99.2,<0.001$ \\
\hline & Before 2006 & 5 & 2912 & $69.70(53.83-85.58)$ & $99.3,<0.001$ \\
\hline \multirow[t]{2}{*}{ Sample size } & $\geq 1000$ & 7 & 61,031 & 78.68 (73.42-83.93) & $99.3,<0.001$ \\
\hline & $<1000$ & 22 & 9006 & $64.21(55.56-72.86)$ & $99.0,<0.001$ \\
\hline \multirow[t]{8}{*}{ Country } & Ethiopia & 15 & 52,508 & 69.75 (65.08-74.43) & $97.9,<0.001$ \\
\hline & Kenya & 5 & 4383 & $45.04(26.05-64.04)$ & $99.4,<0.001$ \\
\hline & Tanzania & 4 & 10,162 & 82.25 (75.35-89.15) & $97.7,<0.001$ \\
\hline & Malawi & 1 & 464 & 80.39 (76.78-84.00) & - \\
\hline & Rwanda & 1 & 68 & 70.59 (59.76-81.42) & - \\
\hline & Somalia & 1 & 1111 & 85.96 (83.92-88.00) & - \\
\hline & Mozambique & 1 & 332 & 37.05 (31.86-42.24) & - \\
\hline & Zimbabwe & 1 & 1009 & $91.97(90.29-93.65)$ & - \\
\hline Overall & & 29 & 70,037 & $67.86(63.59-72.12)$ & $99.2,<0.001$ \\
\hline
\end{tabular}


Table 4 Pooled prevalence of post-abortion family planning methods among women in eastern Africa

\begin{tabular}{lll}
\hline Type of post-abortion family planning methods & Pooled prevalence $\mathbf{9 5 \%}$ & I-squared \\
\hline Injectable & $33.23(22.12-44.34)$ & $99.8, p<0.001$ \\
Implants & $24.71(13.53-35.89)$ & $99.8, p<0.001$ \\
Oral contraceptive pills (OCP) & $23.42(19.95-26.89)$ & $97.5, p<0.001$ \\
Intrauterine devices (IUD) & $9.12(5.36-12.88)$ & $99.0, p<0.001$ \\
Female condom & $7.43(5.17-9.69)$ & $98.2, p<0.001$ \\
Female sterilization & $0.35(0.19-0.89)$ & $95.2, p<0.001$ \\
\hline
\end{tabular}

$69.78 \%(66.00-73.57 \%)$ for post-abortion prevalence after the deletion of a single study (Table 5).

Table 5 Sensitivity analysis of prevalence for each study being omitted with 95\% Cl prevalence of post-abortion family planning methods in eastern Africa

\begin{tabular}{|c|c|c|}
\hline Study omitted & Prevalence & $95 \% \mathrm{Cl}$ \\
\hline Abamecha et al. [15] & 67.67 & $63.31-72.03$ \\
\hline Abebe et al. [18] & 67.30 & $62.95-71.65$ \\
\hline Alemayehu et al. [38] & 67.46 & $62.95-71.96$ \\
\hline Asrat et al. [16] & 67.02 & $62.65-71.39$ \\
\hline Chukwumalu et al. [50] & 67.18 & $62.75-71.61$ \\
\hline Erko et al. [37] & 67.78 & $63.43-72.12$ \\
\hline Evens et al. [20] & 69.78 & $66.00-73.57$ \\
\hline Gallo et al. [48] & 68.95 & $64.75-73.15$ \\
\hline Hagos et al. [36] & 67.74 & $63.38-72.10$ \\
\hline Kassahun [35] & 67.82 & $63.46-72.17$ \\
\hline Kokeb et al. [34] & 68.16 & $63.84-72.48$ \\
\hline Lema and Mpanga [47] & 67.39 & $63.02-71.77$ \\
\hline Mahomed et al. [49] & 66.96 & $62.59-71.33$ \\
\hline Makenzius et al. [42] & 67.58 & 63.19-71.97 \\
\hline Mekuria et al. [33] & 67.47 & 63.09-71.84 \\
\hline Moges et al. [17] & 68.08 & $63.75-72.41$ \\
\hline Muche et al. [32] & 68.64 & $64.38-72.89$ \\
\hline Mutua et al. [41] & 68.34 & $64.27-72.41$ \\
\hline Onyango et al. [40] & 69.21 & $65.13-73.28$ \\
\hline Packer et al. [51] & 67.77 & $63.43-72.11$ \\
\hline Prata et al. [31] & 67.49 & $63.06-71.91$ \\
\hline Rasch et al. [46] & 67.04 & $62.65-71.43$ \\
\hline Rasch et al. [45] & 67.10 & $62.73-71.47$ \\
\hline Samuel et al. [30] & 67.31 & $61.58-73.04$ \\
\hline Seid et al. [29] & 68.56 & $64.28-72.84$ \\
\hline Solo et al. [39] & 68.54 & $64.26-72.82$ \\
\hline Stephens et al. [44] & 67.33 & $62.25-72.42$ \\
\hline Tesfaye and Oljira [28] & 68.26 & $63.95-72.57$ \\
\hline Wanjiru et al. [43] & 67.78 & $63.41-72.15$ \\
\hline
\end{tabular}

Factors associated with post-abortion family planning utilization

Association between marital status and post-abortion family planning utilization

In this meta-analysis, four studies were included to see the association between marital status and post-abortion family planning utilization. Those women who had married marital status were 3.2 times more likely to use family planning during the post-abortion period compared to their counterparts $(\mathrm{AOR}=3.20 ; 95 \%$ CI 2.02-5.05) (Fig. 5).

\section{Association between parity and post-abortion family planning utilization}

Two studies also indicated that multiparity was strongly associated with post-abortion family planning utilization. Multiparous women were 3.84 times more likely to use family planning during the post-abortion period compared to their counterparts $(\mathrm{AOR}=3.84 ; 95 \%$ CI $1.43-$ 10.33) (Fig. 6).

\section{Association between having a history of abortion and post- abortion family planning utilization}

Two studies also indicated that the history of abortion was strongly associated with post-abortion family planning utilization. Those women who had a history of abortion were 2.33 times more likely to utilize family planning during the post-abortion period compared to their counterparts (AOR=2.33; 95\% CI 1.44-3.75) (Fig. 7).

\section{Association between getting counselling on post-abortion family planning and its utilization}

Furthermore, eight study results from the metaanalyses of the study (Fig. 8) have also revealed that getting counselling about post-abortion family planning was a significant factor associated with postabortion family planning utilization of women. Women who had got counselling on post-abortion family planning were 4.63 times more likely to use family planning compared to their counterparts (AOR=4.63; 95\% CI 3.27-6.56) (Fig. 8). 
Study

ID
$\%$

OR $(95 \% \mathrm{CI}) \quad$ Weight

Asrat et al. (2018)

Erko et al. (2016)

Kassahun (2017)

Moges et al. (2018)

Overall (I-squared $=0.0 \%, p=0.819)$

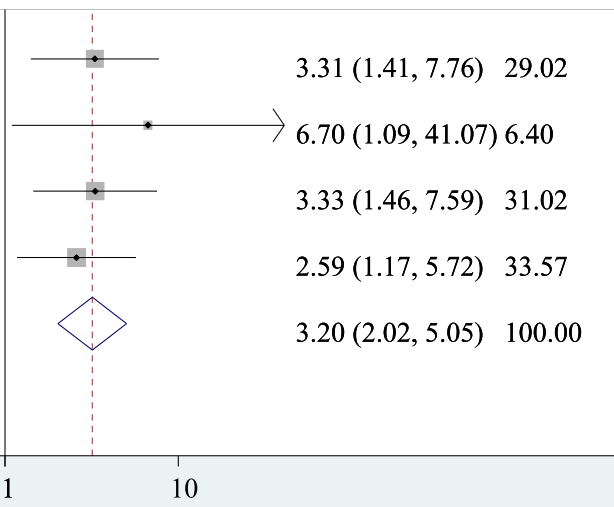

Fig. 5 The overall pooled odds ratio of the association between marital status and post-abortion family planning utilization in Eastern Africa

\section{Association between ever used contraceptives and post- abortion family planning utilization}

In this meta-analysis, three study results revealed that ever used contraceptive method was a significant factor associated with post-abortion family planning utilization. Women who had ever used contraceptive methods were 3.44 times more likely to use family planning compared to those women who had not used contraceptive methods $(\mathrm{AOR}=4.63 ; 95 \% \mathrm{CI}$ 2.27-5.21) (Fig. 9).

\section{Discussions}

Low post-abortion family planning utilization is considered as one of the primary and major causes of induced abortion or spontaneous abortion or stillbirth since most post-abortion women are at risk of pregnancy almost immediately. Therefore, this systematic review and meta-analysis aimed to estimate the pooled prevalence of post-abortion family planning utilization and its associated factors in Eastern Africa. In this meta-analysis, the overall pooled prevalence of post-abortion family
Study

ID
$\%$

OR $(95 \% \mathrm{Cl}) \quad$ Weight

$2.70(1.04,7.02) \quad 67.20$

$7.91(1.66,37.71) 32.80$

$3.84(1.43,10.33) 100.00$

NOTE: Weights are from random effects analysis

$\begin{array}{lll}.0265 & 1 & 37.7\end{array}$

Fig. 6 The overall pooled odds ratio of the association between parity and post-abortion family planning utilization in Eastern Africa 
Study

ID
OR $(95 \% \mathrm{Cl}) \quad$ Weight

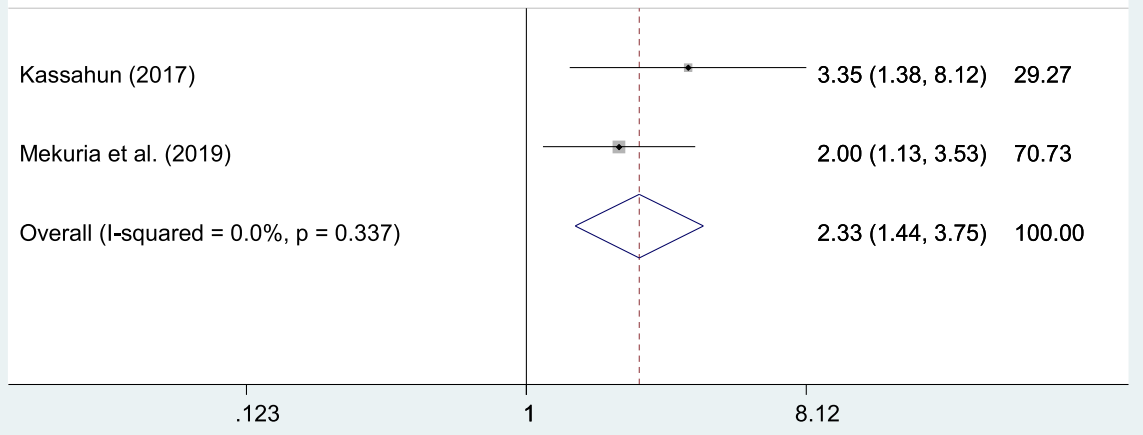

Fig. 7 The overall pooled odds ratio of the association between history of abortion and post-abortion family planning utilization in Eastern Africa

planning utilization in Eastern Africa was 67.86\% (95\% CI 63.59-72.12). This is lower than the study done in Brazil 97.4\% [52], Asia and Sub-Saharan Africa (SSA) 77\% [53], Pakistan 73\% [54], and India $81 \%$ [55]. However, it is higher than a study done in Kenya 60.9\% [56] and Nepal 49.5\% [57]. This might be due to variation in sample size and differences in socioeconomic status, sociocultural values, norms, religious beliefs, and study setting of the study populations. Besides, it might be due to differences in postabortion counselling practices, availability of family planning methods and services, and more than half of the included studies in the final meta-analysis were from Ethiopia.

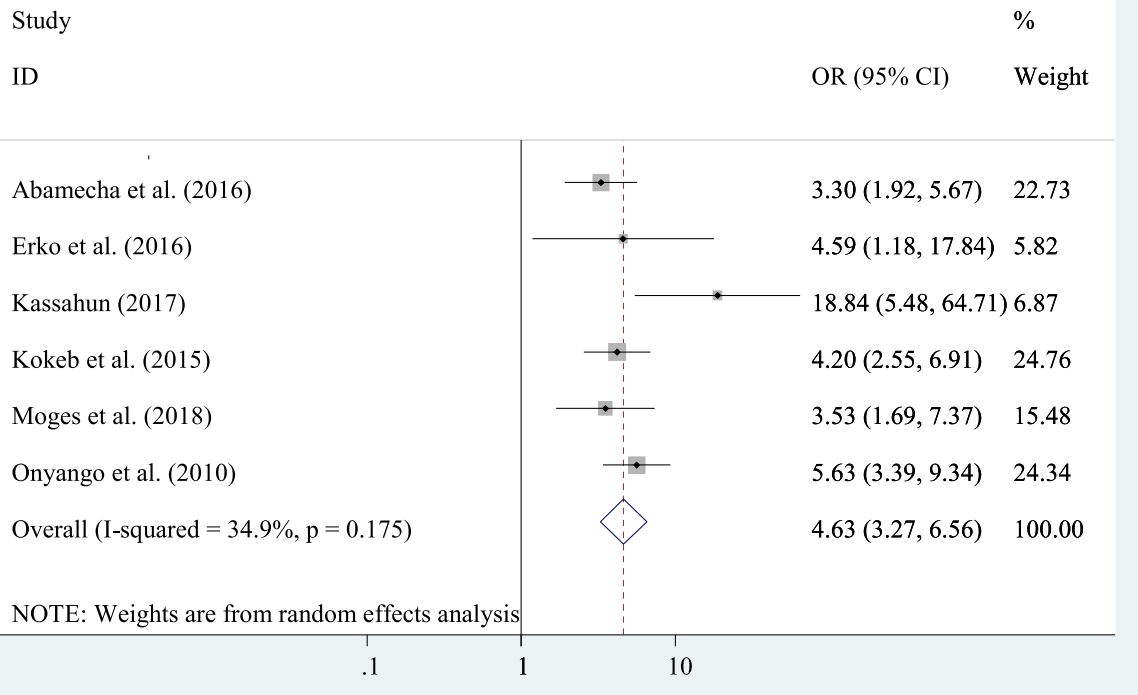

Fig. 8 The overall pooled odds ratio of the association between post-abortion contraceptive counselling and post-abortion family planning utilization in Eastern Africa 


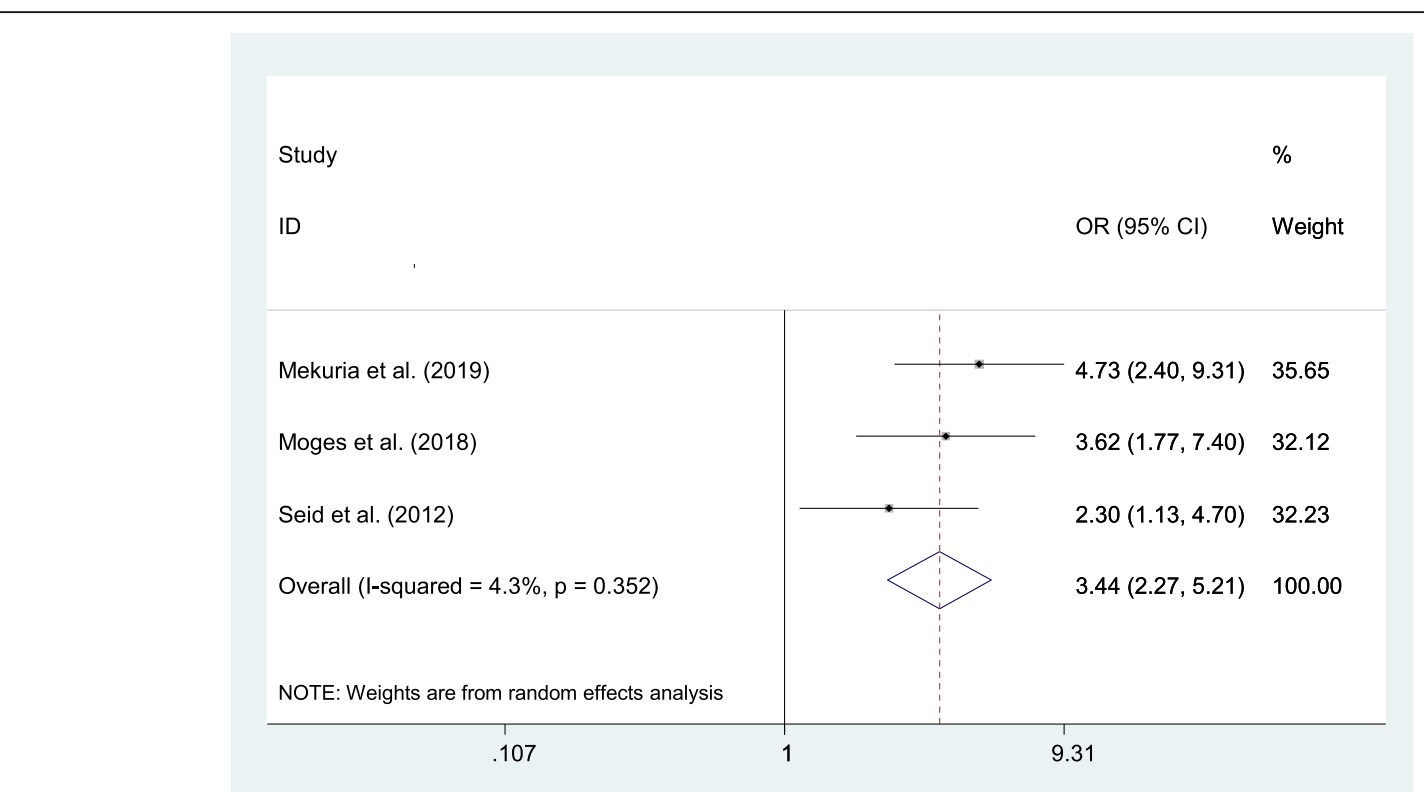

Fig. 9 The overall pooled odds ratio of the association between ever used contraceptives and post-abortion family planning utilization in Eastern Africa

Regarding the subgroup analysis, the highest prevalence was observed in Zimbabwe with 91.97\% (95\% CI 90.29-93.65), and the lowest prevalence was observed in Mozambique with $37.05 \%$ (95\% CI 31.86-42.24). The possible justification could be due to the difference in the participant's level of awareness, educational level, religious beliefs, and various misconceptions and large gaps in the availability and distribution of facilities with basic and comprehensive post-abortion care capabilities across countries. Besides, in Zimbabwe, there is a strong family planning program with one of the highest contraceptive prevalence rates in Sub-Saharan Africa (SSA). Zimbabwe also has a restrictive abortion law, with legal abortion limited to circumstances of rape, incest, fetal impairment, or to save the woman's life $[17,58]$.

In this study, the overall post-abortion family planning utilization was highest in studies published before 2006, which was $69.70 \%$ compared to studies published in 2006. The probable reason might be only five studies with a small sample size that were published before 2006 were included in the analysis, which might contribute to the higher utilization of post-abortion family planning methods. Additionally, those published articles before 2006 also include studies done in Zimbabwe which has one of the lowest abortion rates in Sub-Saharan Africa, likely due to high contraceptive use and a robust family planning program [59].

Regarding the type of post-abortion family planning methods utilized, the most commonly utilized postabortion family planning was injectable 33.23\% (95\% CI 22.12-44.34), implants $24.71 \%$ (95\% CI $13.53-35.89$ ), oral contraceptive pills 23.42\% (95\% CI 19.95-26.89), intrauterine devices 9.12\% (95\% CI 5.36-12.88), and condom 7.43\% (95\% CI 5.17-9.69). This is in line with a study conducted in Brazil, Pakistan, India, and Nepal $[52,54,55,57]$. This might be due to most women preferring to use short-acting methods to conceive after a short period due to higher pregnancy desire. Moreover, it might be due to provider bias towards specific methods, general demand for short-term methods (including the barriers women face in accessing longerterm methods like health care coverage, ongoing source of care, quality of care, disparate access to health information, contraception myths, and increased apprehension of side effects), and supply-related concerns might also contribute.

Women who were married were more likely to utilize post-abortion family planning compared to single women. This finding is consistent with the study conducted in Gondar, Ethiopia [60]. This might be due to married women may be likely to be having sex more regularly than unmarried women, which may explain their high post-abortion family planning utilization. Besides, currently, married women's decision-making power on family planning has been raised $[61,62]$ and contraceptive prevalence continues to increase [63]. Similarly, multiparous women were more likely to utilize post-abortion family planning compared to their counterparts. This might be due to multiparous women who were at higher risk of death due to recurrent abortion, anemia, diabetes mellitus, and other chronic diseases; as a result, they decided to use post-abortion family 
planning for the recommended period before getting pregnant again. Moreover, multiparous women might want to limit their number of children. Additionally, the multiparous mother may feel more confident to decide on post-abortion family planning individually and by discussing with her partner.

The odds of post-abortion family planning utilization were higher among those women who had a history of abortion compared to those women who had not a history of abortion. This might be due to women who had a history of abortion may get counselling on family planning methods, and they became awarded on the use of post-abortion family planning methods. Similarly, the odds of post-abortion family planning utilization were higher among those women who got counselling on family planning methods as compared with their counterparts. This might be explained that women who get counselling about family planning methods may easily understand the risks of frequent pregnancy for women and the growing fetus, which ultimately increases postabortion family planning utilization.

Post-abortion family planning utilization was higher among women who used contraceptives compared to those women who never used any contraceptives. This finding is supported by a study conducted in Pakistan [54]. This might be due to women who ever used contraceptives had previous exposure to family planning services, which might influence the awareness of women towards post-abortion family planning utilization. Besides, there is limited evidence contributing to each pooled odds ratio $(\mathrm{OR})$ result in the final meta-analysis.

\section{Limitations of the study}

The study designs for all primary articles incorporated in this review were cross-sectional; as a result, the confounding variables most of the time might affect the outcome variable. Furthermore, only papers published in English were included in the review. Most of the publications were from a few countries in eastern Africa which may not be representative of the subregion, and there is also a limited sample size from some countries which makes it difficult to conclude for the entire population of the country. Lastly, relevant research published in another language, or not indexed in the selected databases, has been excluded.

\section{Conclusion}

This study revealed that the marital status of the women, multiparity, having a history of abortion, getting counselling on post-abortion family planning, and ever used contraceptives were found to be significantly associated with post-abortion family planning utilization. Therefore, based on the study findings, the authors recommended that policies and protocols should be updated to eliminate barriers such as the requirement that women and adolescents have to be married or have parental or spousal consent for contraceptive services. Advocacy is needed from policymakers and governments for ensuring quality post-abortion family planning services and reducing the unmet need for family planning by giving individualized and patient-centred postabortion family planning counselling and client interaction, upgrading clinical skills on post-abortion contraceptive methods and implementing efforts to reduce stigma. Generally, health systems and providers in Eastern Africa need support to ensure quality PAC in the face of a reportedly high burden of complications arising from unsafe abortion in the subregion. There is a disturbing lack of evidence on PAFP utilization in most countries in the subregion. As a result, little is known about the utilization of PAFP services in the majority of Eastern African countries. Research with longer followup with women, a more rigorous study design with more qualitative support to understand women's reasons for or objections to PAFP, is needed to fill these knowledge gaps.

\section{Abbreviations}

ANC: Antenatal care; Cl: Confidence interval; CSA: Central Statistical Agency; EDHS: Ethiopian Demographic and Health Survey; EMDHS: Ethiopian Mini Demographic and Health Survey; OR: Odds ratio; PAFP: Post-abortion family planning; WHO: World Health Organization

\section{Supplementary Information}

The online version contains supplementary material available at https://doi. org/10.1186/s13643-021-01731-4.

Additional file 1:. Table S1 PRISMA 2009 Checklist

\section{Acknowledgements}

Not applicable.

Authors' contributions

All authors critically reviewed and contributed to the intellectual content of this systematic review and meta-analysis. The authors read and approved the final manuscript.

Funding

The authors did not receive funds from any funding agency.

Availability of data and materials

The dataset supporting the conclusions of this article is available from the authors on request.

\section{Declarations}

Ethics approval and consent to participate

Not applicable

Consent for publication

Not applicable.

Competing interests

The authors declare that they have no competing interests. 


\section{Author details}

${ }^{1}$ School of Nursing, College of Health Sciences, Woldia University, P.O.Box: 400, Woldia, Ethiopia. ${ }^{2}$ School of Midwifery, College of Health Sciences, Woldia University, P.O.Box: 400, Woldia, Ethiopia.

Received: 17 October 2020 Accepted: 1 June 2021

Published online: 09 June 2021

\section{References}

1. (WHO) WHO. Unsafe abortion; global and regional estimates of the incidence of unsafe abortion and associated mortality in 2008. 6th edition, Geneva; Available at: https://apps.who.int/iris/bitstream/handle/10665/4452 9/9789241501118 eng.pdf;jessionid=D3161F9394A9A098D10FD1 5F6D76797E?sequence=1, accessed March 23/2020. 2011.

2. Organization $\mathrm{WH}$. Report of a $\mathrm{WHO}$ technical consultation on birth spacing: Geneva, Switzerland 13-15 June 2005; Available at: https://apps.who.int/iris/ bitstream/handle/10665/69855/WHO_RHR_07.1_eng.pdf? sequence=1\&ua=1; accessed on March 24/2020:: World Health Organization; 2007.

3. WHO. The World Health Organization's safe abortion guidance document: Available at:https://ajph.aphapublications.org/doi/full/10.2105/AJPH.2012.3 01204. American Journal of Public Health 2013;103(4), The World Health Organization's Safe Abortion Guidance Document, 103, 4, 596.

4. Organization WH. Trends in maternal mortality 2000 to 2017: estimates by WHO, UNICEF. UNFPA, World Bank Group and the United Nations Population Division; 2019.

5. WRA WRA. Post abortion family planning: a key component of post abortion care: consensus statement: Availabe at: https://www.glowm.com/ pdf/PAC-FP-Joint-Statement-November2013-final_printquality.pdf, accessed on March 24/2020. 2013

6. Haddad LB, Nour NM. Unsafe abortion: unnecessary maternal mortality. Reviews in obstetrics and gynecology. 2009;2(2):122-6.

7. Say L, Chou D, Gemmill A, Tunçalp Ö, Moller A-B, Daniels J, et al. Global causes of maternal death: a WHO systematic analysis. The Lancet global health. 2014;2(6):e323-e33. https://doi.org/10.1016/S2214-109X(14)70227-X.

8. Organization WH, Health WHOR. Medical eligibility criteria for contraceptive use: World Health Organization; 2010.

9. Rasch V, Huber D, Akande E. Report of the postabortion care technical advisory panel; 2007.

10. Smith R, Ashford L, Gribble J, Clifton D. Family planning saves lives. Washington DC: Population Reference Bureau. 2009;5.

11. Peipert JF, Madden T, Allsworth JE, Secura GM. Preventing unintended pregnancies by providing no-cost contraception. Obstetrics and gynecology. 2012;120(6):1291-7. https://doi.org/10.1097/AOG.0b013e318273 eb56.

12. Melkamu Y, Betre M, Tesfaye S. Utilization of post-abortion care services in three regional states of Ethiopia. Ethiopian Journal of Health Development. 2010;24(1).

13. Keogh SC, Kimaro G, Muganyizi P, Philbin J, Kahwa A, Ngadaya E, et al. Incidence of induced abortion and post-abortion care in Tanzania. PLoS One. 2015;10(9):e0133933. https://doi.org/10.1371/journal.pone.0133933.

14. Mutua MM, Maina BW, Achia TO, Izugbara CO. Factors associated with delays in seeking post abortion care among women in Kenya. BMC Pregnancy Childbirth. 2015;15(1):241. https://doi.org/10.1186/s12884-0150660-7.

15. Abamecha A, Shiferaw A, Kassaye A. Assessment of post abortion contraceptive intention and associated factors among abortion clients In Gambella Health Facilities, Gambella Town, South West Ethiopia. Int J Med Sci Clini Inventions. 2016;3:2061-70.

16. Asrat M, Bekele D, Rominski SD. Post-abortion contraceptive acceptance and choice determinants among women receiving abortion care at Saint Paul's hospital, Addis Ababa, Ethiopia. Ethiopian Journal of Reproductive Health. 2018;10(1):14.

17. Moges Y, Hailu T, Dimtsu B, Yohannes Z, Kelkay B. Factors associated with uptake of post-abortion family planning in Shire town, Tigray, Ethiopia. BMC Res Notes. 2018;11(1):928. https://doi.org/10.1186/s13104-018-4029-7.

18. Abebe AM, Wudu Kassaw M, Estifanos SN. Postabortion contraception acceptance and associated factors in Dessie Health Center and Marie Stopes International Clinics, South Wollo Northeast, Amhara Region, 2017. Int J Reprod Med. 2019;2019:1-10. https://doi.org/10.1155/2019/1327351.

19. Rehnstrom Loi U, Klingberg-Allvin M, Gemzell-Danielsson K, Faxelid E, Oguttu M, Makenzius M. Contraceptive uptake among post-abortion care- seeking women with unplanned or planned pregnancy in western Kenya. Sex Reprod Healthc. 2020;23:100486. https://doi.org/10.1016/j.srhc.2020.1004 86.

20. Evens E, Otieno-Masaba R, Eichleay M, McCARRAHER D, Hainsworth G, Lane C, et al. Post-abortion care services for youth and adult clients in Kenya: a comparison of services, client satisfaction and provider attitudes. J Biosocial Sci. 2014;46(1):1-15. https://doi.org/10.1017/S0021932013000230.

21. Moher D, Shamseer L, Clarke M, Ghersi D, Liberati A, Petticrew M, et al. Preferred reporting items for systematic review and meta-analysis protocols (PRISMA-P) 2015 statement. Systematic Rev. 2015;4(1):1. https://doi.org/10.11 86/2046-4053-4-1.

22. Downes MJ, Brennan ML, Williams HC, Dean RS. Development of a critical appraisal tool to assess the quality of cross-sectional studies (AXIS). BMJ Open. 2016;6(12):e011458. https://doi.org/10.1136/bmjopen-2016-011458.

23. Borenstein M, Hedges LV, Higgins JP, Rothstein HR. A basic introduction to fixed-effect and random-effects models for meta-analysis. Res Synthesis Methods. 2010;1(2):97-111. https://doi.org/10.1002/jrsm.12.

24. Rücker G, Schwarzer G, Carpenter JR, Schumacher M. Undue reliance on 12 in assessing heterogeneity may mislead. BMC Med Res Methodol. 2008;8(1): 79. https://doi.org/10.1186/1471-2288-8-79.

25. Nyaga VN, Arbyn M, Aerts M. Metaprop: a Stata command to perform metaanalysis of binomial data. Archives of Public Health. 2014;72(1):39. https:// doi.org/10.1186/2049-3258-72-39.

26. Sterne JA, Egger M. Funnel plots for detecting bias in meta-analysis: guidelines on choice of axis. J Clin Epidemiol. 2001;54(10):1046-55. https:// doi.org/10.1016/S0895-4356(01)00377-8.

27. Song F, Gilbody S. Bias in meta-analysis detected by a simple, graphical test. Increase in studies of publication bias coincided with increasing use of meta-analysis. BMJ. 1998;316(7129):471.

28. Tesfaye G, Oljira L. Post abortion care quality status in health facilities of Guraghe zone. Ethiopia. Reprod Health. 2013;10(1):35. https://doi.org/10.11 86/1742-4755-10-35.

29. Seid A, Gebremariam A, Abera M. Integration of family planning services within post abortion care at health facilities in dessie-North East Ethiopia. Science, Technology and Arts Research Journal. 2012;1(1):38-46.

30. Samuel M, Fetters T, Desta D. Strengthening postabortion family planning services in Ethiopia: expanding contraceptive choice and improving access to long-acting reversible contraception. Global Health: Science and Practice. 2016;4(Supplement 2):S60-S72.

31. Prata N, Bell S, Holston M, Gerdts C, Melkamu Y. Factors associated with choice of post-abortion contraception in Addis Ababa, Ethiopia. African Journal of Reproductive Health. 2011;15(3):55-62.

32. Muche A, Bewket B, Ayalew E, Demeke E. Utilization of post abortal contraceptive use and associated factors among women who came for abortion service at Debre Berhan Hospital, Debre Berhan, Ethiopia March 2019: institution based cross sectional. Clinical Journal of Obstetrics and Gynecology. 2019;2:025*33.

33. Mekuria A, Gutema H, Wondiye H, Abera M. Postabortion contraceptive use in Bahir Dar, Ethiopia: a cross sectional study. Contraception and reproductive medicine. 2019;4(1):19. https://doi.org/10.1186/s40834-019-0099-8.

34. Kokeb L, Admassu E, Kassa H, Seyoum T. Utilization of post abortion contraceptive and associated factors among women who came for abortion service: a hospital based cross sectional study. J Fam Med Dis Prev. 2015;1:022.

35. Kassahun M. Utilization of post abortion family planning and associated factors among women coming to abortion service in selected abortion clinics at Addis Ababa. Ethiopia: Addis Ababa University; 2017.

36. Hagos G, Tura G, Kahsay G, Haile K, Grum T, Araya T. Family planning utilization and factors associated among women receiving abortion services in health facilities of central zone towns of Tigray, Northern Ethiopia: a cross sectional study. BMC women's health. 2018;18(1):83. https://doi.org/10.1186/ s12905-018-0582-4.

37. Erko E, Abera M, Admassu B. Safe abortion care, utilization of post abortion contraception and associated factors, Jimma Ethiopia. J Women's Health Care. 2016:4(4):5-9.

38. Alemayehu T, Otsea K, GebreMikael A, Dagnew S, Healy J, Benson J. Abortion care improvements in Tigray, Ethiopia: using the Safe Abortion Care $(S A C)$ approach to monitor the availability, utilization and quality of services. Final report of a two-year project in. 2009;50.

39. Solo J, Billings DL, Aloo-Obunga C, Ominde A, Makumi M. Creating linkages between incomplete abortion treatment and family planning services in 
Kenya. Studies in family planning. 1999;30(1):17-27. https://doi.org/10.1111/ j.1728-4465.1999.00017.x.

40. Onyango MA, Oguttu M, Barger M. Predictive factors for uptake of postabortion care in western Kenya. African Journal of Midwifery and Women's Health. 2010;4(3):115-20. https://doi.org/10.12968/ajmw.2010.4.3.48970.

41. Mutua MM, Achia TN, Manderson L, Musenge E. Spatial and socio-economic correlates of effective contraception among women seeking post-abortion care in healthcare facilities in Kenya. PloS one. 2019;14(3).

42. Makenzius M, Faxelid E, Gemzell-Danielsson K, Odero TMA, Klingberg-Allvin M, Oguttu M. Contraceptive uptake in post abortion care-secondary outcomes from a randomised controlled trial, Kisumu, Kenya. PLoS One. 2018;13(8):e0201214. https://doi.org/10.1371/journal.pone.0201214

43. Wanjiru M, Askew I, Munguti N, RamaRao S, Homan R, Kahando R, et al. Assessing the feasibility, acceptability and cost of introducing postabortion care in health centres and dispensaries in rural Tanzania. 2007.

44. Stephens B, Mwandalima IJ, Samma A, Lyatuu J, Mimno K, Komwihangiro J. Reducing barriers to postabortion contraception: the role of expanding coverage of postabortion care in Dar es Salaam, Tanzania. Global Health: Science and Practice. 2019;7(Supplement 2):S258-S70.

45. Rasch V, Yambesi F, Massawe S. Medium and long-term adherence to postabortion contraception among women having experienced unsafe abortion in Dar es Salaam. Tanzania. BMC Pregnancy and Childbirth. 2008; 8(1):32. https://doi.org/10.1186/1471-2393-8-32

46. Rasch V, Massawe S, Yambesi F, Bergstrom S. Acceptance of contraceptives among women who had an unsafe abortion in Dar es Salaam. Tropical Medicine \& International Health. 2004;9(3):399-405. https:/doi.org/10.1111/ j.1365-3156.2004.01197.x.

47. Lema VM, Mpanga V. Post-abortion contraceptive acceptability in Blantyre, Malawi. East African medical journal. 2000;77(9):488-93.

48. Gallo MF, Gebreselassie H, Victorino MTA, Dgedge M, Jamisse L, Bique C. An assessment of abortion services in public health facilities in Mozambique: women's and providers' perspectives. Reprod Health Matters. 2004; 12(sup24):218-26.

49. Mahomed K, Healy J, Tandom S. Family planning counselling--a priority for post abortion care. The Central African journal of medicine. 1997;43(7):2057.

50. Chukwumalu K, Gallagher MC, Baunach S, Cannon A. Uptake of postabortion care services and acceptance of postabortion contraception in Puntland, Somalia. Reprod Health Matters. 2017;25(51):48-57. https://doi. org/10.1080/09688080.2017.1402670.

51. Packer C, Pack AP, McCarraher DR. Voluntary contraceptive uptake among postabortion care clients treated with misoprostol in Rwanda. Glob Health Sci Pract. 2019;7(Supplement 2):S247-S57.

52. Ferreira ALC, Souza Al, Lima RA, Braga C. Choices on contraceptive methods in post-abortion family planning clinic in the northeast Brazil. Reproductive Health. 2010;7(1):5. https://doi.org/10.1186/1742-4755-7-5.

53. Benson J, Andersen K, Healy J, Brahmi D. What factors contribute to postabortion contraceptive uptake by young women? A program evaluation in 10 countries in Asia and sub-Saharan Africa. Global Health: Science and Practice. 2017;5(4):644-57.

54. Azmat S, Hameed W, Ishaque M, Mustafa G, Ahmed A. Post-abortion care family planning use in Pakistan. Pakistan Journal of Public Health. 2012;2(2).

55. Banerjee S, Gulati S, Andersen K, Acre V, Warvadekar J, Navin D. Associations between abortion services and acceptance of postabortion contraception in six Indian states. Studies in Family Planning. 2015;46(4):387-403. https://doi. org/10.1111/j.1728-4465.2015.00039.x.

56. Uwera J. Determinants of modern contraceptive uptake following immediate post abortion counselling among 15--24 year old clients, fhok 2014: University of Nairobi; 2015.

57. Shrestha A, Sharma P. Post abortion choice and acceptance of contraception in Nepal. NJOG. 2013;8(1):14-7.

58. Izugbara C, Wekesah FM, Sebany M, Echoka E, Amo-Adjei J, Muga W. Availability, accessibility and utilization of post-abortion care in Sub-Saharan Africa: a systematic review. Health care for women international. 2020;41(7): 732-60. https://doi.org/10.1080/07399332.2019.1703991.

59. Sully EA, Madziyire MG, Riley T, Moore AM, Crowell M, Nyandoro MT, et al. Abortion in Zimbabwe: a national study of the incidence of induced abortion, unintended pregnancy and post-abortion care in 2016. PloS one. 2018;13(10):e0205239. https://doi.org/10.1371/journal.pone.0205239.
60. Dejenie Seyoum AG, Gizaw Z. Assessment of post abortion contraceptive intention and associated factors among abortion clients in Gondar Town, North West Ethiopia, 2013. 2014.

61. Alemayehu B, Kassa GM, Teka Y, Zeleke LB, Abajobir AA, Alemu AA. Married women's decision-making power in family planning use and its determinants in Basoliben, Northwest Ethiopia. Open Access Journal of Contraception. 2020;11:43, 52, DOI: https://doi.org/10.2147/OAJC.S250462.

62. Belay AD, Mengesha ZB, Woldegebriel MK, Gelaw YA. Married women's decision making power on family planning use and associated factors in Mizan-Aman, South Ethiopia: a cross sectional study. BMC Womens Health. 2016;16(1):1-6.

63. Wang W, Staveteig S, Winter R, Allen C, editors. Women's marital status, contraceptive use, and unmet need in Sub-Saharan Africa, Latin America, and the Caribbean 2017: ICF.

\section{Publisher's Note}

Springer Nature remains neutral with regard to jurisdictional claims in published maps and institutional affiliations.
Ready to submit your research? Choose BMC and benefit from:

- fast, convenient online submission

- thorough peer review by experienced researchers in your field

- rapid publication on acceptance

- support for research data, including large and complex data types

- gold Open Access which fosters wider collaboration and increased citations

- maximum visibility for your research: over $100 \mathrm{M}$ website views per year

At BMC, research is always in progress.

Learn more biomedcentral.com/submissions 